\title{
Modeling and interpreting element ratios in water and sediments: A sensitivity analysis of post-Chernobyl $\mathrm{Ru}$ : Cs ratios
}

\author{
J. Hilton and E. Rigg
}

Institute of Freshwater Ecology, Windermere Laboratory, Far Sawrey, Ambleside, Cumbria, LA22 OLP U.K.

\author{
W. Davison, J. Hamilton-Taylor, and M. Kelly
}

Institute of Environmental and Biological Sciences, University of Lancaster, Lancaster, LA1 4YQ U.K.

\section{F. R. Livens}

Department of Chemistry, University of Manchester, Manchester, M13 9PL U.K.

\section{L. Singleton}

Institute of Terrestrial Ecology, Merlewood Laboratory, Grange over Sands, Cumbria, LA11 6JU U.K.

\begin{abstract}
When elements are simultaneously added to lakes, experimentally or by accident, their ratios in the water phase and in bottom sediments can change with time due to differential partitioning between solution and suspended particles or sediments. A number of equations are developed to show the change of ratio with time in water and sediments assuming simultaneous pulse inputs followed by a range of combinations of loss processes from solution (i.e. hydraulic losses, sorption to particles followed by settling, and diffusion into the sediments). The pattern of events is discussed both for pulse events with specific limiting assumptions and for combined continuous and pulse inputs. The models show that elemental ratios in sediments are generally less sensitive indicators of differential partitioning than are elemental ratios in water. For lakes with long residence times, the long-term elemental ratio in the sediments does not differ from that in the initial spike to the water column, but for short residence times, it is directly dependent on the ratio of either partition or diffusion coefficients.

The models are used to interpret $\mathrm{Ru}$ : Cs ratios measured in the water and sediments of Esthwaite Water subsequent to the pulse input of Chernobyl fallout. The ratios can be explained by assuming nuclides were lost either by flushing and sorption or by flushing, sorption, and diffusion. The process combination of flushing and diffusion is incompatible with the observed constant ratios.
\end{abstract}

Several recent studies have modeled the environmental behavior of radionuclides and heavy metals in lakes using either two (Davison et al. 1993; Robbins et al. 1992) or three process components (Hesslein 1987). In particular, the models assume that the lake is a completely mixed reactor and that material can only be lost by hydraulic flushing, sorption of dissolved forms onto particles followed by transport to the sediments, and-if the concentration in the sediment pore water is lower than in the open water-by direct diffusion to the sediment after molecular diffusion across a benthic boundary layer.

Although the models have been successfully applied to single element distributions, they are unreliable if data are scarce. Many of the parameters in the equations are defined by physical processes which should be independent of the chemical element. Consequently, in models of elemental ratios it should be possible to eliminate some common variables. Elimination of these common variables would improve predictions of the processes of removal from the water when scarce data are available for one of the elements. The same approach can also be used

\section{Acknowledgments}

This work was partially supported by a contract from the Commission of the European Community, Radiation Protection Department. to analyze sediment data where temporal variability is high. Hesslein (1987) showed that ratios of element concentrations in sediments were much more stable. Ratios of elements in particular environmental compartments, such as sediments, water, or suspended particles, can be expected to change if the rate and extent of the transfer between compartments is not the same for each element (e.g. if the elements have different distribution coefficients or diffusion coefficients). In this paper, we derive the equations describing the change, with respect to time of addition to the lake water, in the ratio of two elements in both the water column and the sediment. We then use sensitivity analysis to develop some insights into the processes of transport of radioactive ruthenium in a freshwater lake in the U.K.

\section{Model derivations}

If we assume that two elements behave conservatively, if both dissolved and sorbed element is considered, then three processes must be considered in our models: hydraulic loss (in both dissolved and particulate forms), particle settling, and direct diffusion to the sediments. Hydraulic losses will always take place, but it is possible that only onc of the other processes operates. Alternatively, all three processes could operate together. Our 
model derivation is expressed in terms of $\mathrm{Cs}$ and $\mathrm{Ru}$, but it is equally applicable to other pairs of elements. Our equations do not include terms for radioactive decay, so all data must be decay corrected to the same data (in our case 3 May 1986) before use.

In all the equations, we make the following assumptions. The concentration of neither radioactive element in the particulate form dominates the system to such an extent that the concentration of $\mathrm{Cs}$ and $\mathrm{Ru}$ in the dissolved form becomes unmeasurable. Cs and Ru are supplied to the epilimnion of the lake in a single instantaneous pulse. Sediment accumulation of both $\mathrm{Cs}$ and $\mathrm{Ru}$ takes place uniformly over all the sediment surface. The epilimnion can be considered to be completely mixed, so that outflow concentrations are the same as the concentrations in the surface waters. The sinking. velocities for particulate $\mathrm{Cs}$ and $\mathrm{Ru}$ are the same. Sinking particles appear in the sediments immediately after the attainment of equilibrium for the sorption reaction, without the delay normally observed due to settlement through the water column. The composition of the particles does not change with time (i.e. element $K_{d}$ values are constant). The concentration of $\mathrm{Cs}$ and $\mathrm{Ru}$ in the sediment pore water is much less than the concentration in the open water (i.e. $C_{\text {pore }} \approx 0$ ). This assumption will tend to overestimate the effect of diffusion at low $K_{d}$ when dissolved concentrations in the water column will remain high and at long times when sorption sites in the sediments are full and a significant concentration of dissolved radionuclide builds up in the pore water. For high $K_{d}$ values, such as those used here, this assumption is less likely to cause significant errors (but see discussion). The only way to address this problem is by use of complex, advection-diffusion models near the sediment-water interface. Each of the three process combinations will be considered separately for both the water column and the sediments in the following sections.

Hydraulic loss and particle transport-The concentration of dissolved Cs in the water column is given by (Davison et al. 1993):

$$
C_{t}=C_{0} \exp \left[-\left(F+F K_{d} S+A u K_{d} S\right) t / V\right] .
$$

$C_{t}$ is the concentration of dissolved Cs or $\mathrm{Ru}$ in epilimnetic water at a time $t$ (d) after the initial deposition, $\mathrm{mBq}$ liter $\left.^{-1}\right), C_{0}$ is the initial concentration of dissolved Cs or $\mathrm{Ru}$ in the epilimnion ( $\mathrm{mBq}$ liter $\left.{ }^{-1}\right), F$ is the flow through the lake $\left(\mathrm{m}^{3} \mathrm{~d}^{-1}\right), A$ is the lake area $\left(\mathrm{m}^{2}\right), u$ is the mean particle settling velocity $\left(\mathrm{m} \mathrm{d}^{-1}\right), K_{d}$ is the distribution coefficient of $\mathrm{Cs}$ or $\mathrm{Ru}$ between water and particles $\left(\mathrm{m}^{3}\right.$ $\left.\mathrm{kg}^{-1}\right), S$ is the concentration of particles in the water column $\left(\mathrm{kg} \mathrm{m}^{-3}\right)$, and $V$ is the volume of the well-mixed epilimnetic water $\left(\mathrm{m}^{3}\right)$.

Assuming the same equation holds for both nuclides, although $K_{d}$ will differ, the ratio in the water is given so that

$$
\begin{aligned}
\frac{C^{\mathrm{Ru}}}{C^{\mathrm{Cs}}}=\frac{C_{0}{ }^{\mathrm{Ru}}}{C_{0}{ }^{\mathrm{Cs}}} \exp [ & F S\left(K_{d}{ }^{\mathrm{Cs}}-K_{d}^{\mathrm{Ru}}\right) \\
& \left.+A u S\left(K_{d}{ }^{\mathrm{Cs}}-K_{d}{ }^{\mathrm{Ru}}\right) t / V\right]
\end{aligned}
$$

or

$$
\frac{C_{t}^{\mathrm{Ru}}}{C_{t}^{\mathrm{Cs}}}=R^{w} \frac{C_{0}^{\mathrm{Ru}}}{C_{0}{ }^{\mathrm{Cs}}} .
$$

$R^{w}$, the ratio multiplier for water components, provides an indication of how the ratio of the nuclides in the water at any time differs from the ratio at $t=0$, when the nuclides were first added. It is defined as

$$
R^{w} \equiv \exp \left[(F S+A u S)\left(K_{d}^{\mathrm{Cs}}-K_{d}^{\mathrm{Ru}}\right) t / V\right] .
$$

The flux to the sediments at any time is $A u K_{d} S C_{t}$, where all parameters are as defined above.

By substituting for $C_{t}$ from Eq. 1, the instantaneous flux to the sediments is given by

$$
A u K_{d} S C_{0} \exp \left[-\left(F+F K_{d} S+A u K_{d} S\right) t / V\right],
$$

and the total flux $(\Phi)$ to the bed is obtained by integrating over all time since the introduction of the radionuclide, i.c.

$$
\Phi=\int_{t_{1}}^{t_{2}} A u K_{d} S C_{0} \exp \left[-\left(F+F K_{d} S+A u K_{d} S\right) t / V\right] \mathrm{d} t .
$$

If $t_{1}=0$ and all other parameters, apart from $C$, remain constant with time, then

$$
\Phi=\frac{A u K_{d} S C_{0} V\left\{1-\exp \left[-\left(F+F K_{d} S+A u K_{d} S\right) t / V\right]\right\}}{\left(F+F K_{d} S+A u K_{d} S\right)} .
$$

Hence, the ratio of radionuclides in the sediment is given by Eq. 3 (Table 1) so that

$$
\frac{C_{s}^{\mathrm{Ru}}}{C_{s}{ }^{\mathrm{Cs}}}=R^{s} \frac{C_{0}^{\mathrm{Ru}}}{C_{0}{ }^{\mathrm{Cs}}}
$$

$C_{s}$ is the concentration of $\mathrm{Ru}$ or Cs in the sediment in arbitrary units and $C_{0}$ is the initial concentration of the same radionuclide in the water. $R^{s}$ is the ratio multiplier for sediment components and provides an indication of how the ratio of nuclides in the sediment differs from the ratio of elements originally added to the water at time $t$ $=0$.

Hydraulic and diffusive loss-The concentration in the water column is given by (Davison et al. 1993)

$$
C=C_{0} \exp \left\{-\left[\left(F+F K_{d} S+D A_{m} / z\right) t / V\right]\right\} .
$$

$D$ is the diffusion coefficient of ions at infinite dilution $\left(\mathrm{m}^{2} \mathrm{~d}^{-1}\right), A_{m}$ is the area of sediment exposed to water in the fully mixed epilimnion $\left(\mathrm{m}^{2}\right), z$ is the boundary layer thickness, assumed the same for both ions since it is defined by physical processes (m), and the other parameters are as defined above. If we assume the same equation holds for both nuclides, the ratio in the water is given by

$$
\begin{aligned}
& \frac{C^{\mathrm{Ru}}}{C^{\mathrm{Cs}}}=\frac{C_{0}^{\mathrm{Ru}}}{C_{0}{ }^{\mathrm{Cs}}} \exp \{[ {\left[F S\left(K_{d}^{\mathrm{Cs}}-K_{d}^{\mathrm{Ru}}\right)\right.} \\
&\left.\left.+\left(D^{\mathrm{Cs}}-D^{\mathrm{Ru}}\right) A_{m} / z\right] t / V\right\} .
\end{aligned}
$$

If we assume that the concentration of the element in the sediment pore water is zero, the flux to the sediments 
Table 1. The ratio of $\mathrm{Ru}$ and $\mathrm{Cs}$ concentrations in sediment at time $t_{2}$ after the initial input for a combination of hydraulic flushing and sorption to particles followed by settlement.

$$
\begin{aligned}
\frac{C_{s}{ }^{\mathrm{Ru}}}{C_{s}{ }^{\mathrm{Cs}}}= & \frac{\left(\frac{\left(A u K_{d}{ }^{\mathrm{Ru}} S C_{0}{ }^{\mathrm{Ru}} V\right)\left\{1-\exp \left[-\operatorname{Proc}_{1}(\mathrm{Ru}) t_{2} / V\right]\right\}}{\operatorname{Proc}_{1}(\mathrm{Ru})}\right)}{\left\langle\frac{\left(A u K_{d}{ }^{\mathrm{cs}} S C_{0}{ }^{\mathrm{Cs}} V\right)\left\{1-\exp \left[-\operatorname{Proc}_{1}(\mathrm{Cs}) t_{2} / V\right]\right\}}{\operatorname{Proc}_{1}(\mathrm{Cs})}\right\rangle} \\
= & \frac{C_{0}{ }^{\mathrm{Ru}} K_{d}{ }^{\mathrm{Ru}} \operatorname{Proc}_{1}(\mathrm{Cs})\left\{1-\exp \left[-\operatorname{Proc}(\mathrm{Ru}) t_{2} / V\right]\right\}}{C_{0}{ }^{\mathrm{Cs}} K_{d}{ }^{\mathrm{Cs}} \operatorname{Proc}_{1}(\mathrm{Ru})\left\{1-\exp \left[-\operatorname{Proc}(\mathrm{Cs}) t_{2} / V\right]\right\}} \\
& \text { where } \operatorname{Proc}_{1}(\mathrm{Ru})=F+F K_{d}^{\mathrm{Ru}} S+A u K_{d}{ }^{\mathrm{Ru}} S \\
& \text { and } \operatorname{Proc}_{1}(\mathrm{Cs})=F+F K_{d}{ }^{\mathrm{cs}} S+A u K_{d}{ }^{\mathrm{Cs}} S
\end{aligned}
$$

at any time is $\left(D A_{m} C_{t}\right) / z$. By substituting for $C_{t}$ from Eq. 4 , the instantaneous flux to $C_{t}$ the sediments is given by

$$
D A_{m} C_{0} \exp \left\{-\left[\left(F+F S K_{d}+D A_{m} / Z\right) t / V\right]\right\} / Z,
$$

and the total flux to the bed is obtained by integrating over all time since the introduction of the radionuclide:

$$
\begin{aligned}
\Phi=\int_{t_{1}}^{t_{2}}\left\{D A_{m} C_{0} \exp [-\right. & \left(F+F S K_{d}\right. \\
& \left.\left.\left.+D A_{m} / z\right) t / V\right] / z\right\} \mathrm{d} t .
\end{aligned}
$$

If $t_{1}=0$, then

$$
\Phi=\frac{V D A_{m} C_{0}\left\{1-\exp \left[-\left(F+F S K_{d}+D A_{m} / z\right) t_{2} / V\right]\right\}}{z\left(F+F S K_{d}+D A_{m} / z\right)} .
$$

Hence, the ratio of radionuclide concentrations is given by Eq. 6 (Table 2).

Hydraulic loss, diffusive loss, and particle transportThe concentration in the water column is given by (Davison et al. 1993)

$$
C_{t}=C_{0} \exp \left\{-\left[\left(D A_{m} / z\right)+A u K_{d} S+F+F S K_{d}\right] t / V\right\}
$$

where the parameters are as defined above. If we assume the same equation holds for both nuclides, the ratio in the water is given by

$$
\begin{aligned}
& \frac{C^{\mathrm{Ru}}}{C^{\mathrm{Cs}}}=\frac{C_{0}^{\mathrm{Ru}}}{C_{0}{ }^{\mathrm{Cs}}} \exp \left\langle\left\{\left[\left(D^{\mathrm{Cs}}-D^{\mathrm{Ru}}\right) A_{m} / z\right]\right.\right. \\
&\left.\left.+\left(K_{d}{ }^{\mathrm{Cs}}-K_{d}^{\mathrm{Ru}}\right)(A u S+F S)\right\} t / V\right\rangle .
\end{aligned}
$$

Table 2. Ratio of Ru and Cs concentrations in sediment for a combination of hydraulic flushing and diffusion across a boundary layer.

$$
\begin{aligned}
& \frac{C^{\mathrm{Ru}}}{C^{\mathrm{Cs}}}= \frac{C_{0}{ }^{\mathrm{Ru}} D^{\mathrm{Ru}} \operatorname{Proc}_{2}(\mathrm{Cs})\left\{1-\exp \left[-\operatorname{Proc}_{2}(\mathrm{Ru}) t_{2} / V\right]\right\}}{C_{0}{ }^{\mathrm{cs}} D^{\mathrm{Cs}} \operatorname{Proc}_{2}(\mathrm{Ru})\left\{1-\exp \left[-\operatorname{PrOc}_{2}(\mathrm{Cs}) t_{2} / V\right]\right\}} \\
& \text { where } \operatorname{Proc}_{2}(\mathrm{Cs})=F+F S K_{d}{ }^{C s}+D^{\mathrm{Cs}} A_{m} / z \\
& \text { and } \operatorname{Proc}_{2}(\mathrm{Ru})=F+F S K_{d}^{\mathrm{Ru}}+D^{\mathrm{Ru}} A_{m} / z
\end{aligned}
$$

The flux to the sediments at any time is then $\left(D A_{m} C_{t} / z\right.$ $\left.+A u K_{d} S C_{t}\right)$. Substituting for $C_{t}$ from Eq. 7, the instantaneous flux to the sediments is given by

$$
\begin{aligned}
\left(D A_{m} / z+A u K_{d} S\right) C_{0} \exp \{- & {\left[\left(D A_{m} / z\right)+A u K_{d} S\right.} \\
& \left.\left.+F+F S K_{d}\right] t / V\right\} .
\end{aligned}
$$

The total flux $(\Phi)$ to the bed is then

$$
\Phi=\int_{t_{1}}^{t_{2}}\left(D A_{m} / z+A u K_{d} S\right) C_{0} \exp \left(\operatorname{Proc}_{3} t / V\right) \mathrm{d} t
$$

where $\operatorname{Proc}_{3}=D A_{m} / z+A u K_{d} S+F+F S K_{d}$.

If $t_{1}=0$, this becomes

$$
\Phi=\frac{C_{0}\left(D A_{m} / z+A u K_{d} S\right) V\left[1-\exp \left(\operatorname{Proc}_{3} t / V\right)\right]}{\operatorname{Proc}_{3}} .
$$

Following the pattern above, Eq. 9 (Table 3 ) can be obtained.

\section{Results}

The results of the model were illustrated by calculating time series of values of $R^{w}$ and $R^{s}$ for the ratios of ${ }^{103} \mathrm{Ru}$ and ${ }^{137} \mathrm{Cs}$ in Esthwaite Water with the decay corrected to 3 May 1986, subsequent to the Chernobyl accident (Hilton et al. 1994). Esthwaite Water is a highly eutrophic lake in the English Lake District (mean total $P=30 \mu \mathrm{g}$ liter ${ }^{-1}$; summer mean Chl $a=50 \mu$ liter $^{-1}$; $\max =100$ $\mu \mathrm{g} \mathrm{liter}{ }^{-1}$, Jones et al. 1979). The lake is relatively shallow, with a maximum depth of $15.5 \mathrm{~m}$ and a mean depth of $6.4 \mathrm{~m}$. Its total volume is $6.4 \times 10^{6} \mathrm{~m}^{3}$, with a surface area of $1.004 \times 10^{6} \mathrm{~m}^{2}$ (Ramsbottom 1976). The lake is monomictic, stratifying from April-May to SeptemberOctober. The Chernobyl deposition occurred immediately before stratification, so the radioactivity was fully mixed throughout the water column. Stratification then developed within a few days (Davison et al. 1993). The hypolimnion is normally anaerobic for much of the stratified period. Effectively, all Cs falling onto the catchment was immobilized by sorption to the soil, i.e. was not released and transported into the lake (Davison et al. 1993).

If $\mathrm{Ru}$ and $\mathrm{Cs}$ can only be lost from the system by hydraulic flushing or particle sedimentation, the ratio between the concentrations of $\mathrm{Ru}$ and $\mathrm{Cs}$ in the water at any time will be given by Eq. $2 \mathrm{a}$. Since the $K_{d}$ for Ru will depend on both the Ru species present in the water column and the particle properties, it is not surprising that literature values of the $K_{d}^{\mathrm{Ru}}$ vary by several orders of magnitude (e.g. 10², Bachhuber et al. 1986; 104, Aston and Duursma 1973). Hence, $K_{d}{ }^{\mathrm{Ru}}$ can be used only as a fitting parameter in the model. A value of $10^{4}$ liter $\mathrm{kg}^{-1}$ $\left(=10 \mathrm{~m}^{3} \mathrm{~kg}^{-1}\right)$ has been obtained in laboratory measurements of $K_{d}$ Cs for the sediments of Esthwaite Water (Hilton unpubl.), and a range of values of the same order (2$8 \times 10^{4}$ liter $\mathrm{kg}^{-1}$ ) was measured for water-column samples from Esthwaite Water immediately post-Chernobyl (Hamilton-Taylor et al. unpubl.). We used values of $K_{d}^{\text {Cs }}$ $=10^{4}$ liters $\mathrm{kg}^{-1}, F=4.38 \times 10^{4} \mathrm{~m}^{3} \mathrm{~d}^{-1}$ and $\mathrm{V}=5.165$ $\times 10^{6} \mathrm{~m}^{3}$ (the mean values for $F$ and $V$ in Esthwaite 
Table 3. Ratio of Ru and Cs concentrations in sediment for a combination of hydraulic flushing, diffusion across a boundary layer and sorption to particles followed by settling.

\begin{tabular}{c}
$\frac{C^{\mathrm{Ru}}}{C^{\mathrm{Cs}}}=\frac{C_{0}^{\mathrm{Ru}}\left(D^{\mathrm{Ru}} A_{m} / z+A u K_{d}^{\mathrm{Ru}} S\right)\left\{1-\exp \left[-\operatorname{Proc}_{3}(\mathrm{Ru}) t / V\right]\right\} \operatorname{Proc}_{3}(\mathrm{Cs})}{C_{0}{ }^{\mathrm{Cs}}\left(D^{\mathrm{Cs}} A_{m} / z+A u K_{d}{ }^{\mathrm{Cs}} S\right)\left\{1-\exp \left[-\operatorname{Proc}_{3}(\mathrm{Cs}) t / V\right]\right\} \operatorname{Proc}_{3}(\mathrm{Ru})}$ \\
wherc $\operatorname{Proc}_{3}(\mathrm{Ru})=D^{\mathrm{Ru}} A_{m} / z+A u K_{d}^{\mathrm{Ru}} S+F+F S K_{d}^{\mathrm{Ru}}$ \\
and $\operatorname{Proc}_{3}(\mathrm{Cs})=D^{\mathrm{Cs}} A_{m} / z+A u K_{d}{ }^{\mathrm{Ru}} S+F+F S K_{d}{ }^{\mathrm{Cs}}$ \\
\hline
\end{tabular}

Water for the period subsequent to the Chernobyl event), and calculated values of $R^{w}$ for a series of assumed values for the ratio of the distribution coefficients, $K_{d}^{\mathrm{Ru}} / K_{d}^{\mathrm{Cs}}$ (Fig. 1a). An appreciable deviation of $R^{w}$ from unity at any time after $t=0$ indicates a change in the ratio of $\mathrm{Ru}$ to Cs in the water column at that time, compared to the initial ratio. The extent of these differences depends on the relative magnitudes of the distribution coefficients (Eq. 2b). Figure 1a demonstrates that the ratio of $\mathrm{Ru}$ to Cs measured in the water column with respect to time, as expressed by the valuc of $R^{w}$, is very sensitive to the ratio of the $K_{d}$ values.

Similarly, from the model of removal based on particle settling plus hydraulic flushing, $\mathrm{Ru}$ : $\mathrm{Cs}$ in the sediment at any time $t$ is given by Eq. 3. A plot of the ratio multiplier for sediment concentrations, $R^{s}$, against time for a scries of $K_{d}$ ratios in the water column is given in Fig. 2a.

If we assume that the concentration of both $\mathrm{Ru}$ and $\mathrm{Cs}$ is zero in the interstitial water of the surface sediment and that only direct adsorption and hydraulic flushing are important, then two equations (Eq. 5 and 6) can be dc- rived for $R^{w}$ and $R^{s}$, respectively. Li and Gregory (1974) listed diffusion coefficients for several ions, but they gave no values for any $\mathrm{Ru}$ species. However, diffusion coefficients for charged species fall into relatively narrow bands, depending on the ionic charge. Hence, $\mathrm{Ru}^{3+}$ and $\mathrm{Ru}^{4+}$ are likely to have diffusion coefficients of $<0.50 \times 10^{-4}$ $\mathrm{m}^{2} \mathrm{~d}^{-1}$ at $18^{\circ} \mathrm{C}$. Spezzano et al. (1990) showed that $20 \%$ of the $\mathrm{Ru}$ in irrigation water in an Italian rice paddy was in one of these cationic forms. Spezzano et al. also found most of the dissolved $\mathrm{Ru}$ in irrigation water and in lake water in northern Italy after Chernobyl sorbed to anionic resins, presumably in the form of $\mathrm{RuO}_{4}{ }^{2-}$. This anionic form should have a diffusion coefficient of between 0.60 and $0.81 \times 10^{-4} \mathrm{~m}^{2} \mathrm{~d}^{-1}$. Twenty percent of the total dissolved $\mathrm{Ru}$ in Lago di Viverone after Chernobyl was adsorbed by a non-ionic collector (Spezzano et al. 1990).

Thermodynamically, the most likely inorganic form of non-ionic $\mathrm{Ru}$ is $\mathrm{RuO}_{4}$ (although it could alternatively be organically complexed $\mathrm{Ru}$ ). Calculated values for the diffusion coefficient of $\mathrm{RuO}_{4}$ range from 0.87 to $1.11 \times 10^{-4}$ $\mathrm{m}^{2} \mathrm{~d}^{-1}$, depending on the assumed shape of the moleculc.
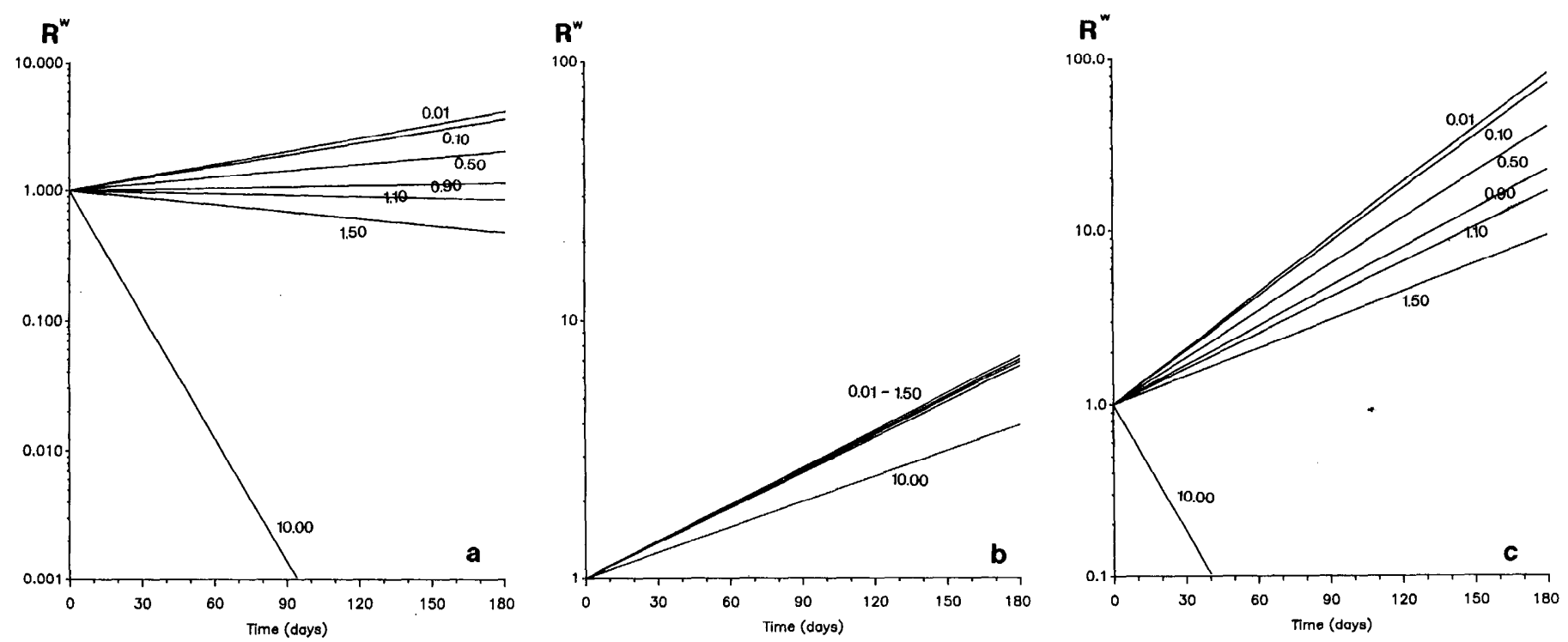

Fig. 1. Plot of the estimated multiplicative factor, $R^{w}$, by which the initial Ru : Cs ratio in the water column of Esthwaite Water would differ from the ratio observed at different times after the deposition event with several different assumed ratios of distribution coefficients $K_{d}^{\mathrm{Ru}}: K_{d}{ }^{\mathrm{Ss}}$ and $D^{\mathrm{Ru}}$ as indicated, assuming dominance by different processes. [a.] Hydraulic flushing and particle deposition. [b.] Direct adsorption and hydraulic flushing. [c.] Direct adsorption, particle deposition, and hydraulic flushing. Values of variables were obtained from measurements or the literature as follows: $A=1.004 \times 10^{6} \mathrm{~m}^{2} ; u=1 \mathrm{~m} \mathrm{~d}^{-1} ; S=0.004 \mathrm{~kg} \mathrm{~m}{ }^{-3}$; $V=5.165 \times 10^{6} \mathrm{~m}^{3} ; F=43,800 \mathrm{~m}^{3} \mathrm{~d}^{-1} ; K_{d}^{C s}=10 \mathrm{~m}^{3} \mathrm{~kg}^{-1} ; D^{C s}=1.53 \times 10^{-4} \mathrm{~m}^{2} \mathrm{~d}^{-1} ; D^{\mathrm{Ru}}=0.69 \times 10^{-4} \mathrm{~m}^{2} \mathrm{~d}^{-1}$ except for panel b where $D^{\mathrm{Ru}}=0.99 \times 10^{-4} \mathrm{~m} \mathrm{~d}^{-1}, A_{m}=0.409 \times 10^{6} \mathrm{~m}^{2}$, and $z=400 \mu \mathrm{m}$. 

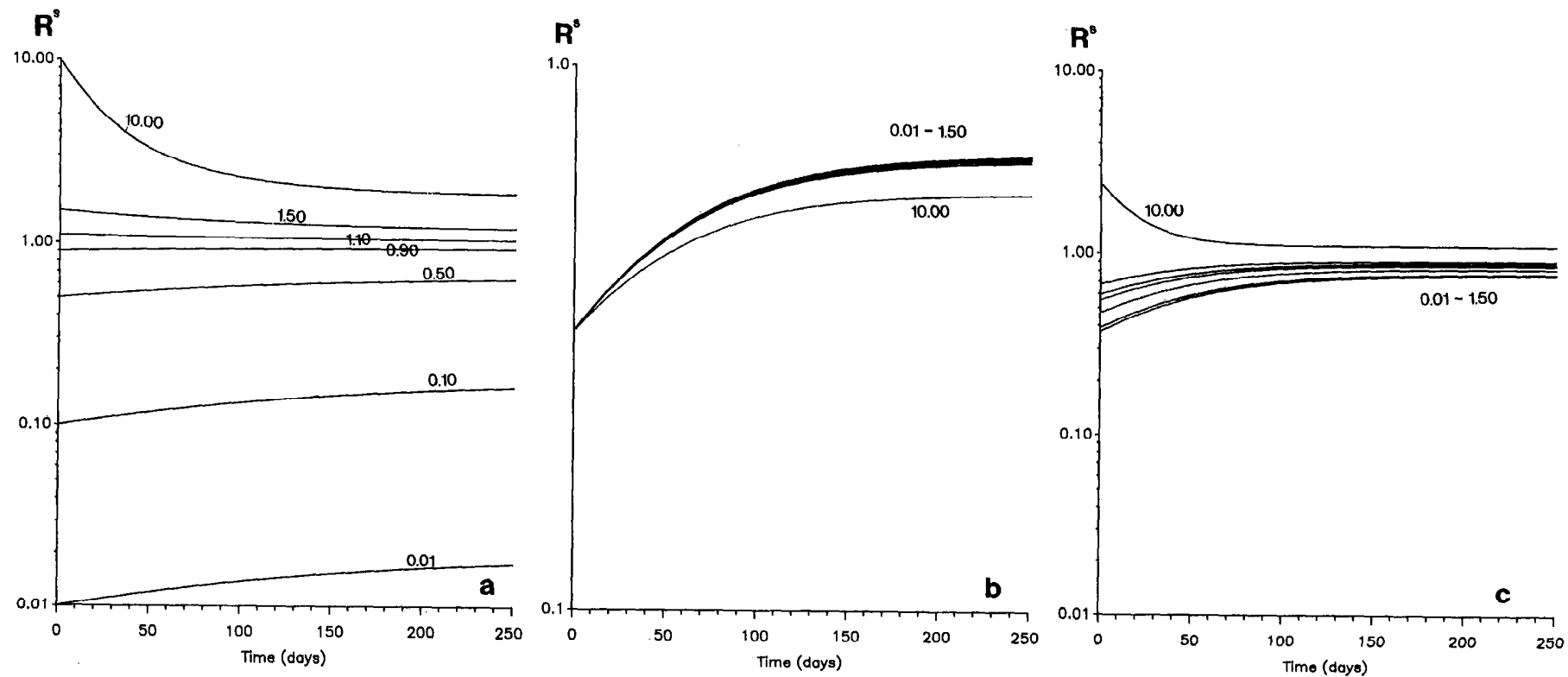

Fig. 2. As Fig. 1, but for the estimated multiplicative factor, $R^{s}$. Values of the other variables were obtained from measurements or the literature and are given in the legend of Fig. 1 except for panel $\mathrm{b}$ where $D^{\mathrm{Ru}}=0.5 \times 10^{-4} \mathrm{~m} \mathrm{~d}^{-1}$.

Values of $D^{\mathrm{Cs}}=1.53 \times 10^{-4} \mathrm{~m}^{2} \mathrm{~d}^{-1}(\mathrm{Li}$ and Gregory 1974), $A_{m}=0.409 \times 10^{6} \mathrm{~m}^{2}, z=400 \mu \mathrm{m}$ (Hilton and Nolan unpubl. results), and mean values of the diffusion coefficients for each $\mathrm{Ru}$ chemical species were substituted into Eq. 5. The resulting plot for $D=0.99 \times 10^{-4} \mathrm{~m} \mathrm{~d}^{-1}$ (Fig. $1 b$ ) shows an increase in $R^{w}$ with time. Smaller values of the Ru diffusion coefficients showed faster increases with time. A plot of $R^{s}$ against time is shown in Fig. $2 \mathrm{~b}$. The variation in $R^{s}$ for $D=0.5 \times 10^{-4} \mathrm{~m} \mathrm{~d}^{-1}$ is relatively small, changing rapidly from a ratio of 0.3 at day 1 to a ratio of 0.7 within $20-30 \mathrm{~d}$. Higher initial ratios, 0.47 and 0.64 , were obtained for $D=0.7 \times 10^{-4}$ and $D=$ $0.99 \times 10^{-4} \mathrm{~m} \mathrm{~d}^{-1}$, respectively, rising to 0.8 and 0.9 , respectively, within $30 \mathrm{~d}$.

A corresponding pair of equations ( 8 and 9) can be constructed if we assume all three processes are occurring simultaneously. Changes with time of $R^{w}$ and $R^{s}$ calculated from this model with the input data for Esthwaite Water given above and $D^{\mathrm{Ru}}=0.70 \times 10^{-4} \mathrm{~m}^{2} \mathrm{~d}^{-1}$ - the mean value for the anionic ruthenate form -are shown in Figs. 1c and 2c.

\section{Discussion}

General application-The differential equations describing the loss of a constituent from the water column as a result of all three scenarios are first order with respect to the concentration of the constituent (Davison et al. 1993). Therefore, the concentrations in the water column can be expressed as exponential functions of timc (Eq. 1, 4 , and 7). If we extend these ideas to the ratio of one constituent to another, the ratio of the constituents remaining in the water column is also an exponential function of time in all three scenarios (Eq. 2b, 5, and 8). Hence, a plot of $\log R^{w}$ vs. time will be a straight line in all three cases (Fig. 1).
For the hydraulic loss and particle settling case (Fig. 1a), the slope of the lines depends on the difference in distribution coefficients, $K_{d}$, for the two elements. When $K_{d}^{\mathrm{Cs}}=K_{d}^{\mathrm{Ru}}$, the right-hand side of Eq. 2 b reduces to unity, consistent with there being no mechanism for differential partitioning of the elements. As a result, their ratio in the water column remains unchanged. Different values of $K_{d}$ mean that at any given time more of one element will be associated with particles, resulting in preferential removal. Consequently, the ratio of the elements remaining dissolved in the water will vary with time. The asymmetry of $R^{w}$ with respect to the ratio of $K_{d}^{\mathrm{Cs}}: K_{d}^{\mathrm{Ru}}$ observed in Fig. 1a stems from the use of a constant value of $K_{d}^{\text {cs }}$ in Eq. $2 \mathrm{~b}$, which is a function of the differences in $K_{d}$ values rather than differences in their ratio.

For the hydraulic loss and direct diffusion case (Fig. $1 \mathrm{~b}$ ), the slope of the lines is determined by the relation between values of the diffusion coefficients, the $K_{d}$ values, $F S$, and $A_{m} / z$. Only cases in which $D^{\mathrm{Ru}}<D^{\mathrm{Cs}}$ have been considered, so all the lines have positive slopes in Fig. $1 \mathrm{~b}$, but negative slopes would result if $D^{\mathrm{Ru}}>D^{\mathrm{Cs}}$. Diffusion coefficients of elements do not differ from one another by more than an order of magnitude; in contrast, distribution coefficients can be many orders of magnitude different. Therefore, changes in elcmental ratios might be expected to be more dramatic if particle settling, rather than direct diffusion, is the mechanism of removal. However, when realistic values of $D, K_{d}$, and other constants are selected, as in Fig. 1, the direct diffusion mechanisms appears to be more likely to bring about a change in elemental ratios. The combined case, involving hydraulic flushing, particle settling, and direct diffusion, has been plotted for realistic values of $D^{\mathrm{Ru}}$ and $D^{\mathrm{Cs}}$ while allowing the ratio of the partition coefficients, $K_{d}$, to vary (Fig. 1c). For most cases in Fig. 1c, the ratio of the elements has a positive slope which seems to be dominated by the direct 
Table 4. The inventory of a substance in the sediment accumulated over a given time period, resulting from a combination of continuous and pulse inputs.

$$
\Phi=f \frac{\alpha}{\beta}\left(\tau_{2}-\tau_{1}\right)+f \frac{\alpha}{\beta^{2}}\left[\exp \left(-\beta \tau_{2}\right)-\exp \left(-\beta \tau_{1}\right)\right]-\frac{f C_{0}}{\beta}\left[\exp \left(-\beta t_{2}\right)-\exp \left(-\beta t_{1}\right)\right]
$$

where

$$
f=\frac{D A}{z}+A u K_{d} S
$$

adsorption term (cf. Fig. 1b), but it is possible to have a negative slope if the particle uptake mechanism dominates.

When the partitioning of elements is substantial due to large differences in $K_{d}$ or $D$ values, resulting in steep slopes in Fig. 1, the more easily removed element would soon be depleted to concentrations below the detection limit. In order to obtain accurate elemental ratios and so deduce mechanisms and perhaps ratios of $K_{d}$ or $D$, measurements must be made at relatively short intervals (weeks) after a spiked addition. Note that the elemental ratios in the water column are independent of the rate of hydraulic flushing, as this general dilution process does not bring about any partitioning between the elements. It does, however, contribute to the removal of both elements and so, if the flushing rate is high, detection limits will be more quickly approached.

To consider how the elemental ratios in the sediments change with time, it is constructive to first focus on the case of hydraulic flushing and particle settling. Equation 3 for this combination reduces to Eq. 10 when $t$ tends to infinity:

$$
R_{\infty} s=\frac{K_{d}^{\mathrm{Ru}}\left[F+(F+A u) K_{d}^{\mathrm{Cs}} S\right]}{K_{d}^{\mathrm{Cs}}\left[F+(F+A u) K_{d}^{\mathrm{Ru}} S\right]} .
$$

When flushing is dominant in normal lakes where the suspended solids concentration, $S$, is relatively small, as in this example, the terms in brackets in Eq. 10 tend to $F$ and cancel, so that $R_{\infty}{ }^{s}$ reduces to $K_{d}^{\mathrm{Ru}}: K_{d}^{\mathrm{cs}}$; that is, the long-term ratio in the sediment is determined by the ratio of the partition coefficients. When flushing is very slow, $R_{\infty}{ }^{s}$ reduces to unity, implying that there is no measurable change in the elemental ratios. This deduction can be conceptually appreciated by considering that if there is no flushing, all the elements must be eventually recruited to the sediment. Whereas changes in elemental ratios in the water column are unaffected by the rate of flushing, the long-term ratio in sediments is determined by the efficiency with which flushing removes the less strongly bound element from the system. Figure $2 \mathrm{a}$ demonstrates that $R^{s}$ does indeed approach asymtotic values. For this figure, a constant value of $K_{d}$ Cs was chosen and $K_{d}^{\mathrm{Ru}}$ was varied. Hence, in our example when $K_{d}^{\mathrm{Ru}} \geq K_{d}^{\mathrm{Cs}}$ both values are large; flushing, consequently, is of minor importance, and $R^{s} \rightarrow 1$. Conversely, when $K_{d}^{\mathrm{Ru}}<K_{d}^{\text {cs }}$, $K_{d}^{\mathrm{Ru}}$ becomes relatively small and flushing becomes more important; $R^{s}$ is consequently observed to approach values close to $K_{d}^{\mathrm{Ru}}: K_{d}^{\mathrm{Cs}}$.
When the elements are first recruited to the sediments, their ratio reflects the ratio of the distribution coefficients irrespective of the flushing rate, since at that time, no different flushing has occurred in the water column. The same reasoning applies to the case of hydraulic flushing coupled to direct adsorption. For the example data, flushing was not very important, so the asymtotic value tends to unity (Fig. 2b). Moreover, for $D^{\mathrm{Ru}}=0.5 \times 10^{-4} \mathrm{~m}$ $\mathrm{d}^{-1}$, the minimum ratio of $D$ values was 0.326 , which represents the maximum excursion from unity at $t=0$.

Clearly then, in lakes with long water residence times, differences in elemental ratios in the sediments will be apparent only for a short period (weeks) after the initial spiking event, since, at longer times, the more slowly differing element will have time to catch up. If particle settling dominates and flushing is rapid, the value of the long-term ratio in the sediment provides a measure of the ratio of $K_{d}$ values if the initial ratio of the elements is known. Similarly, for the direct adsorption case with rapid flushing, the long-term sediment ratio provides a measure of the ratio of diffusion coefficients. This latter ratio, however, is unlikely to differ sufficiently from unity for it to be measured.

It is worth noting that calculated values of $R^{s}$ are based on the integrated sediment record assuming that the concentrations are well mixed in the sediment or homogenized before measurement. For time scales less than a year, as considered here, this will always be the case; for longer times, finely stratified samples may not represent the integrated case.

Equations 1-9 constitute special cases of a more general equation which includes a continuous input and considers radioactive decay. Equation 11 can be derived for the concentration of a substance in the water column by using a simple mass-balance approach after a pulse input in the presence of a continuous input:

$$
\begin{gathered}
C_{W}=\frac{\alpha}{\beta}[1-\exp (-\beta \tau)]+C_{0} \exp (-\beta t) ; \\
\alpha=\frac{\Gamma}{V}
\end{gathered}
$$

and

$$
\beta=\frac{F+F S K_{d}+\frac{D A}{z}+A u K_{d} S+\lambda}{V} .
$$


$\Gamma$ is deposition in $\mathrm{Bq} \mathrm{d}^{-1}, \lambda$ is the radioactive decay rate $\mathrm{d}^{-1}, \tau$ is time from start of constant input, and $t$ is time from pulse input.

Similarly, the inventory in the sediment over a known time period is given by Eq. 12, Table 4 .

The three special cases given earlier can be obtained by putting $\Gamma=0$ and either $K_{d}$ or $D=0$. The pulse input can be removed by putting $C_{0}=0$ when $\Gamma \neq 0$.

$\tau$ may or may not cqual $t$. If a discharge of an artificial radionuclide started with a pulse but continued with a lower, steady discharge, then $\tau=t$. Conversely, if the continuous input has been present for a long time, independent of a pulse input (e.g. natural ${ }^{210} \mathrm{~Pb}$ input), then $\tau \rightarrow \infty$ and Eq. 11 and 12 simplify to

$$
C_{W}=\frac{\alpha}{\beta}
$$

and

$$
\Phi=f \frac{\alpha}{\beta}\left(t_{2}-t_{1}\right)
$$

for water and sediment, respectively. In the water column, the steady state concentration resulting from a continuous input is determined by the mean concentration calculated from the continuous input rate, reduced in proportion to the total of the loss process rates.

In the earlier examples with only pulse inputs, two assumptions concerning the sediment are implicit: the two nuclides do not move independently in the sediments, and the sediment sample contains the surface layer and is sufficiently thick that it contains all the inventory. This assumption is reasonable for a pulse input at relatively short times (a few years) after the input. However, for a continuous input, an increase in the thickness of a sediment slice increases the amount of radioactivity in the sample. Since a pulse is retained close to the surface, the amount of radioactivity is independent of the slice thickness, so the ratio between a continuously input element and a second element input as a pulse will be a function of the sediment sample size. Hence, when comparing a pulse input with a continuous input, a fixed depth of sediment must be chosen for ratio comparisons.

Application of the model to available $\mathrm{Ru} / \mathrm{Cs}$ data-The loss of dissolved substances from lakes occurs through some combination of hydraulic flushing, uptake by particles and subsequent sedimentation, and diffusive flux into the bottom sediments (Hesslein 1987; Robbins et al. 1992; Davison et al. 1993). Given that element fractionation can be expected as a result of particle uptake through differences in $K_{d}$ and as a result of diffusive flux through differences in $D$, it would be surprising if Ru:Cs ratios remained constant through time in both the water column and bottom sediments. However, Hilton et al. (1994) showed that no significant differences could be observed between the ${ }^{103} \mathrm{Ru}:{ }^{137} \mathrm{Cs}$ ratios in various samples collected from the period of Chernobyl deposition (3 May $1986)$ to the end of 1986 . The ratio for Cumbrian rainfall collected during the Chernobyl deposition was $1.64 \pm 0.57$; for epilimnetic water from Esthwaite Water, which was collected 4 months; (120 d) after the deposition, it was 1.70 0.22 ; for bottom sediments from Esthwaite Water in the [early period $(<70 \mathrm{~d})$, it was $1.87 \pm 0.17$; and in the later period (70-230 d), 1.94 \pm 0.45$]$; and for Windermere bottom sediments in the early period ( $<70 \mathrm{~d})$, it was $2.22 \pm 1.12$ and in the later period (70-230 d), $2.41 \pm 0.65$.

These measured ranges of $\mathrm{Ru}: \mathrm{Cs}$ can be converted into limits on $R^{w}$ and $R^{s}$ with only a few simple assumptions. The initial input ratio could be assumed to have either a zero (or very small) variability or, at the other likely extreme, the same variability as the appropriate Ru:Cs measured at different times after the initial input. In the former case, the variability of $R^{w}$ or $R^{s}$ will be proportionally the same as the measured ratio; in the latter case, it will be $1.4\left(=2^{1 / 2}\right)$ times the variability of the measured ratio. Since the former is the more rigorous test, we will assume those conditions. Hence, if a normal distribution is assumed, addition or subtraction of two proportional standard deviations to the initial value of $R^{s}$ or $R^{w}(=1)$ will give an indication of the range of ratios expected for $95 \%$ of the time if $R^{w}$ and $R^{s}$ do not differ from 1 . Thus, there is only a $5 \%$ chance that in Esthwaite water, $R^{w}$ will be $>1.26$ or $<0.74$ within $120 \mathrm{~d}$. Similarly, there is only a $5 \%$ chance that $R^{s}$ will neither exceed 1.18 or be $<0.82$ within $70 \mathrm{~d}$ or will neither exceed 1.46 nor become $<0.54$ within the period 70-230 d. An insight into the implications of this observation is given by carrying out sensitivity analyses of simple models incorporating the values of $R^{w}$ and $R^{s}$ described above.

The results of such an analysis show that if only hydraulic flushing and particle settling are active, $K_{d}^{R u}$ is unlikcly to be significantly different from $K_{d}^{\mathrm{Cs}}$ (see Figs. $l a$ and $2 a$ ). From the measured range of $R^{w}$, there is only a $5 \%$ chance that $K_{d}^{\mathrm{Ru}}$ will be outside the range $1.032-$ $0.975 \times 10^{4}$ liters $/ \mathrm{kg}^{-1}$. A similar conclusion is reached from the ratio $R^{s}$, where the range in $K_{d}^{\mathrm{Ru}}(230 \mathrm{~d})$ is $1.16-$ $0.76 \times 10^{4}$ liters $/ \mathrm{kg}^{-1}$.

If hydraulic flushing were operating in conjunction with only direct diffusion, the condition of a constant Ru:Cs ratio could not be maintained in the water column. Even with the largest probable value of $D^{\mathrm{Ru}}$, equivalent to $\mathrm{RuO}_{4}{ }^{2-}$, the ratio of $\mathrm{Ru}$ to $\mathrm{Cs}$ in the water would have doubled after $50 \mathrm{~d}$, and it could not have remained within the measured bounds by $120 \mathrm{~d} . R^{s}$ is less sensitive than $R^{w}$, and given that $\mathrm{Ru}$ and Cs were first observed in the sediment about a month after the initial atmospheric deposition, the sedimentary record has little diagnostic power.

If all three loss processes were working simultaneously, then, from Eq. 8, $R^{w}$ can equal unity only if

$$
-\left(D^{\mathrm{Ru}}-D^{\mathrm{Cs}}\right) A_{m} / z=\left(K_{d}^{\mathrm{Ru}}-K_{d}^{\mathrm{Cs}}\right) S u A,
$$

which for the data set given in Fig. 1 reduces to

$$
\left(K_{d}^{\mathrm{Ru}}-K_{d}^{\mathrm{Cs}}\right)=-\left(D^{\mathrm{Ru}}-D^{\mathrm{Cs}}\right) \times 2.5 \times 10^{5} .
$$

For the per-ruthenate ion $\left(\mathrm{RuO}_{4}{ }^{2-}\right)$, the most commonly observed form of radioactive $\mathrm{Ru}$ in aquatic sys- 
tems, the diffusion coefficient will be $0.70 \times 10^{-4} \mathrm{~m}^{2} \mathrm{~d}^{-1}$. Hence, for equality to occur, $K_{d}^{\mathrm{Ru}}=3.1 \times 10^{4}$ liters $\mathrm{kg}^{-1}$, with a range from 3.6 to $2.1 \times 10^{4}$ for an assumed boundary layer thickness of $400 \mu \mathrm{m}$ and $K_{d}^{\text {Cs }}$ of $10^{4}$. It is obvious from comparison of Figs. 1c and 2c that, as with the previous combination of processes, $R^{s}$ is not a sensitive indicator of $K_{d}$ differences.

The combined results of these models suggest that a simple combination of hydraulic flushing and direct adsorption to the sediments cannot explain the constancy of $\mathrm{Ru}$ : Cs observed in Esthwaite Water by Hilton et al. (1994). Combinations of hydraulic flushing with either particle settling alone or both particle settling and direct adsorption to the sediments can explain the observations. If the direct diffusion process is not operating for either element, then $K_{d}^{\mathrm{Ru}}$ is the same order of magnitude as $K_{d}^{\mathrm{Cs}}$ $\left(10^{4}\right.$ liters $\left.\mathrm{kg}^{-1}\right)$, and if it operates for both elements, $K_{d}^{\mathrm{Ru}}$ is a factor of 2-4 higher than $K_{d}^{\mathrm{Cs}}$.

Coughtrey and Thorne (1983) reported only one freshwater study in which $K_{d}^{\mathrm{Ru}}$ was measured $\left(10^{3}\right.$ liters $\left.\mathrm{kg}^{-1}\right)$, but comparison with marine studies suggests that a range of $10^{2}-10^{5}$ liters $\mathrm{kg}^{-1}$ should be considered. More recent work by Santschi et al. (1990) reported measured values of $10^{5}-10^{6}$ liters $\mathrm{kg}^{-1}$ in Swiss lakes after Chernobyl, although these $K_{d}$ values were obtained by comparing the activity on solids caught in a sediment trap with dissolved activities in the water column at the same depth. Robbins et al. (1992) used a model to interpret sediment trap data from Lake Constance and inferred that $K_{d}^{\mathrm{Ru}}$ was in the range 6-17 $\times 10^{4}$ liters $\mathrm{kg}^{-1}$. The ranges of $K_{d}^{\mathrm{Ru}}$ values deduced from this work are consistent with the literature values given by Coughtrey and Thorne (1983) and Robbins et al. (1992) but are a little lower than those given by Santschi et al. (1990). The spread of $K_{d}^{\mathrm{Ru}}$ in the literature is not surprising, as $K_{d}^{\mathrm{Ru}}$ is likely to change drastically depending on its chemical speciation at any particular site. Hence, given the similarity of the estimates of $K_{d}^{\mathrm{Ru}}$ from the two different combinations of processes, it is not possible to choose between the two process combinations without other information, such as an in situ $K_{d}^{\mathrm{Ru}}$ in Esthwaite Water or the sedimenting flux derived from a sediment trap.

These model studies highlight the sensitivity of the ratios of radionuclide concentrations in both waters and sediments to differences in $K_{d}$, diffusion coefficient, and process dominance. Elemental ratios in sediments tend to be less sensitive than they are in water-the effects in the latter increasing with time.

\section{References}

Aston, S. R., ANd E. K. DuUrsma. 1973. Concentration effects on Cs-137, Zn-65, Co-60 and Ru-106 sorption by marine sediments, with geochemical implications. Neth. J. Sea Res. 6: $225-240$.

BACHHUBER, H., K. Bunzl, AND W. SChimmack. 1986. Spatial variability of distribution coefficients of Cs-137, Zn-65, Sr85, Co-57, Cd-109, Ce-141, Ru-103, Tc-95m and I-131 in a cultivated soil. Nuclear Technol. 2: 359-371.

Coughtrey, P. J., AND M. C. Thorne. 1983. Radionuclide distribution and transport in terrestrial and aquatic ecosystems: A critical review of data. V. 1. Balkema.

Davison, W., J. Hilton, J. Hamilton-Taylor, F. Livens, AND M. KELLY. 1993. The transport of Chernobyl-derived Cs137 through two freshwater lakes in Cumbria. J. Environ. Radioact. 19: 125-153.

Hesslein, R. H. 1987. Whole-lake metal radio tracer movement in fertilized lake basins. Can J. Fish. Aquat. Sci. 44(suppl. 1): 74-82.

Hilton, J., AND OTHERS, 1994. Similarities in the behaviour of Chernobyl derived Ru-103, Ru-106 and Cs-137 in two freshwater lakes. Aquat. Sci. 56: 133-144.

Jones, J. G., M. J. L. G. Orlandi, AND B. M. Simon. 1979. A microbiological study of sediments from the Cumbrian lakes. J. Gen. Microbiol. 115: 37-48.

LI, Y.-H., AND S. GREGORY. 1974. Diffusion of ions in sea water and deep sea sediments. Geochim. Cosmochim. Acta 38: 703-714.

RamsBottom, A. E. 1976. Depth charts of the Cumbrian lakes. Freshwater Biol. Assoc. Sci. Publ. 33.

RoBbins, J. A., AND ATHERE. 1992. Epilimnetic scavenging of Chcrnobyl radionuclides in Lake Constance. Geochim. Cosmochim. Acta 56: 2339-2361.

Santschi, P. H., S. Bollhalder, S. ZingG, A. Luck, and K. FARRENKOTHEN. 1990. The self-cleaning capacity of surface waters after radioactive fallout. Evidence from European waters after Chernobyl, 1986-1988. Environ. Sci. Technol. 24: 519-527.

Spezzano, P., R. Giacomelli, S. Bortoluzzi, M. Montalto, AND M. NOCENTE. 1990. Construction of a mobile filter system for the determination of the concentration and physico-chemical speciation of radionuclides in natural waters. ENEA, RT/AMB/90/19.

Submitted: 2 June 1993 accepted: 22 February 1995 amended: 6 June 1995 